\title{
Correction to: Which Privacy Policy Works, Privacy Assurance or Personalization Declaration? An Investigation of Privacy Policies and Privacy Concerns
}

\author{
Fue Zeng ${ }^{1} \cdot$ Qing Ye ${ }^{1} \cdot$ Zhilin Yang $^{2,3} \cdot$ Jing $\mathrm{Li}^{4} \cdot$ Yiping Amy Song ${ }^{5}$
}

Published online: 17 November 2020

(c) Springer Nature B.V. 2020

\section{Correction to: Journal of Business Ethics https://doi.org/10.1007/s10551-020-04626-X}

The initial online publication contained a typesetting mistake in the author information. The original article has been corrected.

Publisher's Note Springer Nature remains neutral with regard to jurisdictional claims in published maps and institutional affiliations.

The original article can be found online at https://doi.org/10.1007/ s10551-020-04626-x.

Jing Li

jingli@nju.edu.cn

Fue Zeng

zfee@sina.com

Qing Ye

morningyq@gmail.com

Zhilin Yang

mkzyang@cityu.edu.hk

Yiping Amy Song

amy.song@neoma-bs.fr

1 Department of Marketing, Economics and Management School, Wuhan University, Wuhan 430072, China

2 School of Management, China University of Mining and Technology, Xuzhou, Jiangsu 221116, China

3 Department of Marketing, College of Business, City University of Hong Kong, Hong Kong 852, China

4 Department of Marketing and E-commerce, School of Business, Nanjing University, Nanjing 210093, China

5 Department of Marketing, NEOMA Business School - Campus de Reims, Reims 51100, France 